\title{
Legislar para preservar el patrimonio documental mexicano: un reto para el nuevo milenio
}

\author{
MARÍA IDALIA GARCÍA AgUILAR \\ Centro Universitario de Investigaciones Bibliotecológicas \\ Universidad Nacional Autónoma de México \\ Pulga@ cuib.laborales.unam.mx
}

\begin{abstract}
En Memoria de Jesús Yhmoff Cabrera
$Y$ cuando de libros se trata, ciertos gestos tranquilizan. Hay contactos de manos que son criminales
\end{abstract}

Arturo Pérez-Reverte El Club Dumas



\section{RESUMEN}

Las líneas de este trabajo reflexionan sobre el escaso nivel de protección de los bienes bibliográficos y documentales que hay en México y la necesaria atención que requieren como elementos importantes del patrimonio cultural. Una adecuada salvaguarda de estos bienes culturales sólo podrá establecerse a largo plazo si se reconoce que la ley vigente no respeta su especial naturale$\mathrm{za}$, y que por tanto se requiere de una legislación especial. Es importante y necesario que disciplinas como la bibliotecología, participen en esta problemática desde la formación y la investigación.

Palabras clave: Patrimonio documental; Legislación cultural; Patrimonio cultural.

\section{LEGISLATING FOR THE PRESERVATION OF MEXICAN DOCUMENTARY PATRIMONY: \\ A CHALLENGE FORTHE NEW MLLENNIUM \\ MARÍA IDALIA GARCÍA-AgUILAR}

\section{ABSTRACT}

This study is a reflection on the dearth of legislative protection for bibliographic and documentary property in Mexico and the importance of such provisions for these elements of our cultural patrimony. Adequate safeguards for these cultural properties can be established only for the long term once it is recognized that current legislation does not respect their special na ture and, therefore, a new, specialized legal framework is needed. It is important, and moreover necessary, that the Library Science profession be involved in this problem both formatively and with research. Key Words: Documental heritage; Cultural legislation; Cultural heritage. 


\section{EL PATRIMONIO DOCUMENTAL: UN PROBLEMA DE VARIAS CARAS}

L a adecuada salvaguarda del patrimonio documental mexicano requiere, entre otras cosas, una toma de conciencia de su importancia dentro del conjunto de nuestro patrimonio cultural y, en consecuencia, la elaboración de normas específicas de cumplimiento general que permitan su adecuada protección. Nuestros libros antiguos y documentos históricos representan, sin lugar a dudas, una riqueza colectiva que hasta ahora ha tenido un escaso reconocimiento social e institucional como valuarte cultural y traza histórica.

México es una nación que poseeun amplio conjunto de acervos documentales de gran trascendencia histórica que cuentan con un importante aprecio en el mercado del libro mundial. Sin embargo, a diferencia de lo que sucede en otros países, aquí escasamente se conocen esos materiales, fuera de grupos reducidos de especialistas y bibliófilos que por diversos motivos han encontrado en ellos una singular materia de estudio. Algunos otros (pocos sin duda), han descubierto en ellos una razón de fe y se han propuesto defenderlos.

Sin embargo estos acervos, pese a cualquier reconocimiento, no han alcanzado una consideración prioritaria en el conjunto de las políticas culturales encargadas de la protección y conservación del patrimonio cultural mexicano. En la actualidad siguen siendo éstos los bienes culturales más marginados del panorama cultural mexicano, independientemente de la existencia de un reconocimiento simple en las normativas estatales. La frágil naturaleza física que les es propia a tales documentos, los convierte en testimonios culturales que corren un alto riesgo de pérdida irreparable. Esta condición empeora por dos simples razones: por un lado, el desconocimiento total de la conformación y ubicación exacta de los fondos, y por tanto de la riqueza singular de algunas unidades; por el otro, la escasa atención que han tenido en un proyecto nacional y general cuya finalidad sea su adecuada salvaguarda. Pero también, hay que aclararlo, por el escaso interés que las comunidades de profesionistas han puesto en la formación de recursos humanos que cuenten con los conocimientos especiales que se requieren para su adecuado conocimiento y preservación.

Empero en los últimos años se ha presentado un cambio interesante: aquél que se manifiesta en el interés por conocer la riqueza de estos acervos, lo cual es visible en la elaboración de catálogos e inventarios: instrumentos de control. Sin embargo este interés no es el resultado de políticas y preocupaciones nacionales sino de intereses particulares, y por tanto representa únicamente casos aislados que para describir y tener un control interno emplean una diversidad de mecanismos y dispositivos que a largo plazo representarán una dificultad para ser integrados en la aspiración más básica que se pretende para la protección de esta riqueza patrimonial: un catálogo colectivo para los bienes bibliográficos y un censo general para los bienes documentales.

Esta dispersión de la información, así como los diversos instrumentos utilizados, se integra a un trabajo institucional de manera fragmentada, pues cada entidad resuelve de la mejor manera posible y respondiendo a necesidades inmediatas. 
El conocimiento obtenido con base en esta parcelación no posibilita la valoración que le corresponde a esta enorme riqueza cultural, herencia de un pasado histórico compartido.

En efecto, todaintención por proteger elementos del patrimonio cultural de una nación, debe, en principio, conocer con detalle aquellos objetos que pretende salvaguardar para las generaciones venideras; $\mathrm{y}$ tales objetos no se protegen sin una valoración justificada socialmente. Todo lo contrario, del conjunto general estos objetos siempre se han distinguido, unos más que otros, por su mayor representación y significado como testimonios de hechos históricos que nos proporcionan elementos de identidad colectiva. Pero es imposible coordinar tareas conducentes a la protección de bienes de naturaleza cultural, sin un profundo análisis previo de todas las particularidades y problemáticas que los afectan, pero especialmente de las características que hacen especiales a los objetos por proteger. Ciertamente no se puede proteger aquello que no se conoce.

Sin embargo hablar de protección de fondos antiguos de bibliotecas y de archivos históricos en México significa hablar de un territorio que representa una dificultad añadida: el campo jurídico. Los objetos culturales requieren de una protección especial por sus características propias, pero además especialmente por la enorme tarea que representa conocer su totalidad y, especialmente, difundir su existencia al conjunto dela sociedad. Llevar a cabo estaimportante tarea de protección significa a su vez, el necesario reconocimiento de las obligaciones y responsabilidades que competen tanto a las instituciones que los conservan, como a los poderes públicos que deben garantizar su adecuada salvaguarda. Pero también requiere que se explicite la responsabilidad social y el alcance real de ésta.

\section{LA IMPORTANCIA DE LA CATEGORÍA JURÍDICA DE PROTECCIÓN}

La protección jurídica de los bienes del patrimonio cultural ha sido una preocupación orientada por diversos esfuerzos, que a lo largo del siglo XX han proporcionado resultados importantes tanto a nivel nacional como internacional. A pesar de que resulte lamentable, la destrucción de este patrimonio ha sido paralela a la conciencia de la necesidad de su protección.

Esta conciencia tuvo sus mayores efectos tanto humanos como materiales, después de la Segunda G uerra Mundial. Sin embargo las medidas de protección sobre objetos cuya naturaleza hoy reconocemos cultural, comenzaron desde el siglo XIX y como resultado de este interés diversos países consolidaron grandes catálogos nacionales de estas riquezas. México no escapó a esta tendencia pero no logró consolidar inventarios generales que sirvieran como fundamento a la protección estatal que ha caracterizado al siglo XX.

La tendencia general de esta protección es perceptible en la elaboración de una ley general que determina cuáles objetos de naturaleza cultural son susceptibles de 
ser protegidos como herencia social. El camino recorrido para alcanzar la conformación de este marco jurídico, es resultado de la evolución que ha tenido la valoración de objetos culturales en cada país. Por lo mismo, las definiciones que se incluyen en cada legislación corresponden directamente a términos que provienen de distintas disciplinas y por tanto a distintos marcos teóricos de explicación. Así, no resulta extraño que la utilización de términos provenientes de distintas disciplinas, empleados en ocasiones como sinónimos, no sean realmente tales.

Naturalmente al haber sido elaboradas las concepciones teóricas en las que se insertan estos términos en diversos momentos históricos, responden a procesos de valoración que pueden ser coincidentes pero que en realidad son distintos; responden al tiempo histórico en que fueron elaboradas. Lo que explica que en algún momento tales términos hayan sido denominados históricos o artísticos.

Este proceso de valoración se reflejará de forma directa en el establecimiento de aquellas categorías jurídicas que componen el marco de la protección. Respondiendo al reconocimiento de un pasado histórico, compuesto por diversas manifestaciones culturales, la categoríajurídica tenderá siempre a distinguir sólo a ciertos objetos producidos por un grupo social determinado. Empero, por el alcance de la protección, la catego ría debe responder a características generales compartidas por un grupo de objetos, sean éstos muebles o inmuebles. Tengamos siempre presente que la categoría pretende ubicar o identificar objetos de naturaleza cultural y por tanto no puede ser específica, ya que de otro modo no se propiciaría la protección sino todo lo contrario.

De los términos que se utilizan para definir tanto al conjunto de bienes como a aquéllos que son relevantes, es el de bien cultural el que más adopciones ha tenido, especialmente en el ámbito internacional. El concepto ha evolucionado considerablemente a lo largo de los años. Podemos decir que el documento denominado Carta de A tenas (1931) es el que comienza a delinear las características del bien cultural. La reunión de especialistas que produjo este documento tenía por finalidad consolidar un texto de valor internacional tendiente a resaltar la importancia de la valoración cultural y por ende la protección de objetos con valor artístico e histórico.

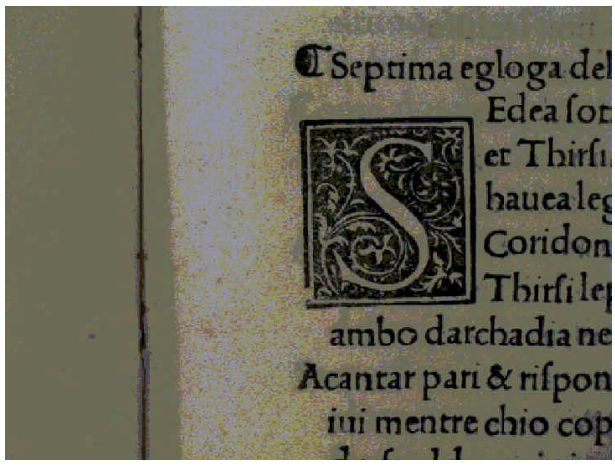

Biblioteca Eusebio Francisco Kino Fotografía Idalia García 
Empero no será hasta después de concluidos los conflictos bélicos con la creación de la O rganización de las Naciones Unidas y el grupo de instituciones especializadas que se fundan inspiradas en los mismos principios, como es el caso particular de la UNESCO, cuando las tareas conducentes a definir las particularidades y elementos que componen el patrimonio cultural comenzarán a dar resultados tangibles, especialmente en lo que se refiere a acuerdos generales y compartidos.

No es extraño que sea en una resolución internacional y sustancialmente de inspiración antibélica, en la que encontremos el reconocimiento de los objetos considerados como bienes culturales. Así, el primer artículo de la Convención de la Haya (1954), dedicada a la protección de objetos de naturaleza cultural en caso de guerra, reconoce como bienes culturales, independientementede su propietario y origen a:

a) Los bienes, muebles o inmuebles, que tengan una gran importancia para el patrimonio cultural de los pueblos, tales como los monumentos dearquitectura, de arte o de historia, religiosos o seculares, los campos arqueológicos, los grupos de construcciones que por su conjunto ofrezcan un gran interés histórico o artístico, las obras de arte, manuscritos, libros y otros objetos de interés histórico, artístico o arqueológico, así como las colecciones científicas y las colecciones importantes de libros, de archivos o de reproducciones de los bienes antes definidos.

b) Los edificios cuyo destino principal y efectivo sea conservar o exponer los bienes culturales muebles definidos en el apartado a), tales como los museos, las grandes bibliotecas, los depósitos de archivo, así como los refugios destinados a proteger en caso de conflicto armado los bienes culturales muebles definidos en el apartado a).

c) Los centros que comprendan un número considerable de bienes culturales definidos en los apartados a) y b) que se denominarán centros monumentales. ${ }^{1}$

D esgraciadamente, esta composición del patrimonio cultural se perderá en el texto más conocido y difundido de los documentos de la UNESCO relativos a este patrimonio: la Convención para la protección del Patrimonio Mundial Cultural y Natural (1972). Especialmente se notará la ausencia en lo que se refiere a los acervos documentales, que prácticamente desaparecerán de esta normativa internacional citada. No será hasta 1992, con la creación del Programa MEMO RIA D EL MUND 0 de la UNESCO, cuando reaparecerán en la mira de una preocupación mundial. Este programa está dedicado especialmente a estos acervos y su objetivo es rescatar, reproducir y promover los tesoros documentales de la humanidad. Pero también tiene la intención de reconocer los objetos documentales de mayor importancia para la cultura universal y de elaborar con ellos una lista mundial, a semejanza de la creada para el Patrimonio Cultural de la Humanidad.

Así este programa reconoce que:

1 Alfredo J. Morales. Patrimmio históicoartística conservacoón debienes alturales Madrid : Historia 16, 1996. p. 9-10. 
[...]la memoria de los pueblos del mundo es de vital importancia para conservar las identidades culturales, para unir el pasado con el presente y para determinar el futuro. El patrimonio documental que se encuentra en bibliotecas y archivos constituye una parte primordial de esta memoria y reflejala diversidad de los pueblos, de las lenguasy de las culturas; sin embargo, esa memoria es frágil. ${ }^{2}$

Al igual que con los otros bienes del patrimonio cultural, es la conciencia de la destrucción la que inspira acciones concertadas para garantizar su salvaguarda. Para apuntalar estos argumentos se presentó, en 1996, el informe Memoniadd Mundo, Me mriaperdida: archivosybiblictecasdestruidosend sigoXX, en donde se resalta que la destrucción efectuada por causas naturales es paralela a la realizada por acciones humanas, sobre todo la negligencia en la falta de protección.

Sin embargo es necesario distinguir dos aspectos principales en la postura de este programa. El primero es el reconocimiento de un conjunto de objetos como patrimonio documental, lo que incluye, además de libros, a documentos y manuscritos y aquellos materiales contenidos en cualquier medio o soporte (como pueden ser los documentos electrónicos y las películas fílmicas), así como también a los documentos audiovisuales, las reproducciones digitales y las tradiciones orales. El segundo aspecto subraya la importancia que tienen las instituciones que custodian estos materiales, es decir los archivos y las bibliotecas, y por ello sus esfuerzos están notablemente dirigidos a ellas. Este reconocimiento institucional le da mayor alcance a la protección, pues de una u otra manera libra la valoración de la apreciación estética o histórica como condición singular para otorgar protección. Al mismo tiempo también unifica un problema poco resuelto, el que se refiere a los términos que definen a dichos objetos culturales.

Es quizás aquí donde el concepto de bien cultural cobra renovada vigencia y vitalidad, en tanto quela valoración del objeto a proteger queda determinada por su pertenencia al conjunto de bienes que aportan una referencia a la historia de la civilización. ${ }^{3}$ No obstante esta nueva concepción no ha alcanzado en México estatus de norma jurídica. La normativa vigente para la protección del patrimonio cultural en México sigue siendo la Leyfeelaral sdremmumentosyzanasarquedógicsartísticosehistóicosde 1972, que en su artículo $36^{\circ}$ inciso segundo y tercero reconoce como monumentos históricos a:

II.- Los documentos y expedientes que pertenezcan o hayan pertenecido a las oficinas y archivos de la Federación de los Estados o de los Municipios y de las casas culturales.

III.- Los documentos originales manuscritos relacionados con la historia de México y los libros, folletos y otros impresos en México o en el extranjero, durante los

2 Abid Abdelaziz. Mentriadd Munda consevandonuettropatrimmiodbametal. México : Comisión Nacional de los Estados Unidos Mexicanos para laUNESCO :UNAM. CUIB :UAEH :UAEM, 1998. p. 5.

3 Alfredo J. Morales. Op at. p. 12. 
siglos XVI a XIX que por su rareza e importancia para la historia mexicana, merezcan ser conservados en el país.

Es así como esta ley establece categorías generales de protección que se refieren a los monumentos arqueológicos, históricos y artísticos. El mismo orden de presentación revelaya un proceso de valoración. Por tanto seguimos manteniendo unavaloración basada en categorías decimonónicas que no corresponden al desarrollo del pensamiento conservacionista y que, por esta misma condición, dificultan la valoración que no corresponda a esos límites impuestos. Por supuesto la especial singularidad del concepto bien cultural, aplicada a la evaluación de objetos contemporáneos que aún no pueden probar su valor histórico o artístico, los deja fuera de esta protección. Es ésta una característica muy especial, porque se refiere directamenteal acrecentamiento del patrimonio cultural que, como tal, no logra consolidarse en México.

El artículo anterior al citado de esta ley, de carácter general, establece que "son monumentos históricos los bienes vinculados con la historia dela nación, a partir del establecimiento de la cultura hispánica en el país, en los términos de la declaratoria respectiva o por determinación de la Ley." Siguiendo este planteamiento jurídico, los bienes conservados en archivos y bibliotecas de México serán considerados siempre y cuando cumplan con este prerrequisito: estar vinculados a la historia de la nación y cumplir con las generalidades expresadas en el artículo $36^{\circ}$; es decir relacionarse con la historia de México, independientemente del lugar en que hayan sido elaborados.

Este razonamiento origina una pregunta sustancial: ¿cómo determinar esta vinculación histórica para los libros y los documentos? Pero también podríamos preguntarnos ¿a qué historia nos referimos y quién la determina?. Ciertamente una valoración de esta naturaleza resulta vaga e imprecisa si lo que buscamos es consolidar una verdadera salvaguarda de nuestro patrimonio documental. Sin embargo existe una condición que dificulta aún más esta importante tarea: la ausencia de participación real de las instituciones encargadas de su custodia.

En efecto debe depositarse en las instituciones nacionales, en este caso el Archivo G eneral de la Nación y en la Biblioteca Nacional de México, la responsabilidad para elaborar los instrumentos generales de control que nos permitan conocer la dimensión de esta riqueza patrimonial. Sobre este aspecto particular de la problemática haremos mención más adelante.

\section{EL PROYECTO PRIORITARIO Y PEN DIENTE: EL REGISTRO E INVENTARIO EN LA LEGISLACIÓN VIGENTE}

Francisco Vidargas escribió en 1994 que "pese a las legislaciones que se han sucedido a lo largo de este siglo, y los convenios internacionales suscritos por el gobierno mexicano, las principales causas de la destrucción de monumentos y sitios 
patrimoniales siguen siendo la corrupción, la ignorancia y la falta de recursos." 4 E stas tres condiciones ciertamente se cumplen en lo que respecta a nuestro patrimonio documental, sin embargo pese a reconocerlo constantemente no logramos cambiar dicha situación y aunque resulte lamentable aceptarlo, el ordenamiento jurídico vigente no coadyuva en nada a cambiar las condiciones de salvaguarda ni resalta la importancia que tiene su conservación y tampoco le otorga a nuestro patrimonio documental el mismo lugar de reconocimiento que sí obtienen otros bienes de naturaleza cultural.

Sería injusto declarar que las acciones conducentes a la protección efectiva del patrimonio cultural en México no se realizan y que no tienen efectos concretos. Debemos reconocer que en lo referente a los bienes bibliográficos la tarea emprendida por la Biblioteca Nacional de Antropología e Historia por ejemplo, que comenzó con el proyecto de los Fondos Conventuales, ha desarrollado un trabajo loable. Sin embargo éste podría ser sustancialmente mejorado.

Pese a esta importante tarea de importancia nacional, habría que reconocer también que no se está prestando igual atención a todos los bienes que componen nuestro interesante y diverso entramado histórico. Los alarmantes casos presentados el año pasado, como el documento robado de Fray Junípero Serra y la quema del archivo histórico dela ciudad de Q uiroga, son tan solo manifestaciones de una problemática que está presente a lo largo y ancho del territorio mexicano.

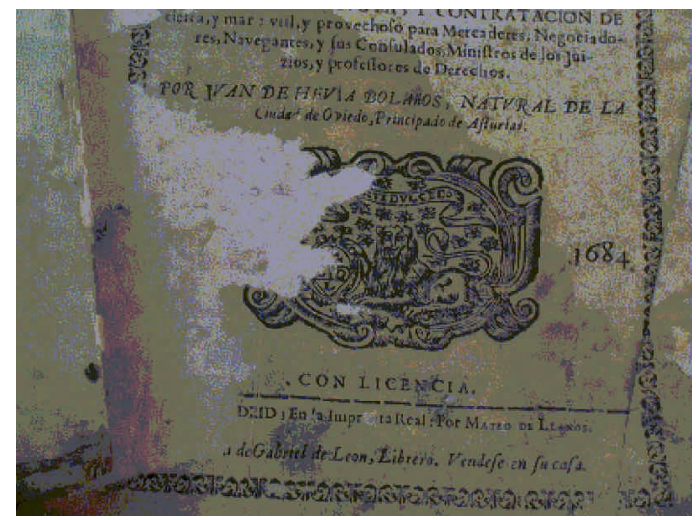

Fondo antiguo Universidad Autónoma de Aguascalientes

Fotografía Idalia García

Pareciera que la protección jurídica fuera el último elemento por considerar al examinarse la salvaguarda del patrimonio documental, cuando en realidad constituye la garantía de continuidad de todo programa y política tendiente a su conservación y

4 Francisco Vidargas. "Introducción". En Lasociedaddivil frenteal patrimmioaltural. México. UNAM. Instituto de Investigaciones Estéticas, 1997. p. 11. 
difusión. Incluso permite determinar la naturaleza social de esta pertenencia, lo que impide o delimita los riesgos que conlleva la valoración puramente económica en el mercado de arte existente.

Esto quiere decir que se convierte en prioridad social su conservación y disfrute en aquellos acervos que se encuentran bajo la custodia de las instituciones públicas, pero también privadas. La función de la norma jurídica, por tanto, debería crear un espacio de equilibrio entreambos intereses cuidando queel beneficio colectivo nunca fuera violentado. En sentido general:

[...] debe permitir la coexistencia de intereses particulares divergentes a través de reglas que deben servir para hacer menos frecuentes y menos ásperos los conflictos, y de otras reglas que deben servir para resolverlos después de que hayan surgido; la función de dirigir intereses divergentes hacia un fin común a través de reglas imperativas y generalmente restrictivas. ${ }^{5}$

Pero todavía no logramos consolidar ni definir un inventario o registro general de nuestro patrimonio cultural que nos permita actuar allí donde más falta hace. Tal instrumento representaría sustancialmentela posibilidad de tener constancia eidentificación formal de los bienes culturales que son patrimonio común de todo el Estado, y por tanto debería ser éste el ente gestionador. Además, la coordinación y cooperación de su compilación, control y publicidad de forma unificada son tareas que le corresponden al Estado en tanto garante de los derechos culturales de los ciudadanos.

Sólo mediante tal instrumento, como mecanismo de conocimiento, podrían diseñarse políticas especiales de defensa del patrimonio cultural que contaran con la concurrencia de la sociedad que los ha heredado. Pero también representaría una herramienta fundamental de comunicación entre administraciones estatales y facilitaría mucho las tareas de salvaguarda, que requieren de la cooperación de diversas instituciones tanto públicas como privadas.

A demás este instrumento de control permitiría que en la necesaria distinción que se realiza al valorar los objetos culturales, pudieran conocerse con certeza aquellos que por sus características deban ser protegidos de forma especial por poseer dos elementos fundamentales: unicidad y singular relevancia. D e esta manera, se podría evaluar con mayores elementos el conjunto de bienes culturales del paísy, se posibilitaría el trámite administrativo que los declara como objetos distintivos, tanto en el ámbito nacional como internacional. En efecto, una declaratoria oficial requiere de la presentación de un informe previo que proporcione todos los elementos conocidos que justifican tal lugar dentro del patrimonio cultural.

Sin embargo para que sea posible consolidar este instrumento deben cumplirse dos requisitos básicos: primero, que se determine su elaboración desde el marco jurídico y segundo, que dentro de estemarco se establezcan sus características y las responsabilidades institucionales de su conformación. Un modelo único de registro permitiría, además, que el intercambio de información sea más accesible. No bastaría con tener

5 Norberto Bobbio. Contribunióna la teeńa de Dexeho Madrid : D ebate, 1990, p. 276-275. 
una ley de aplicación general, se haría necesario determinar el tipo de información que se recopilaría para hacer la valoración cultural de los objetos patrimoniales.

Ésta es, a mi entender, una de las principales carencias de la ley vigente: la falta de definición específica sobre los instrumentos de control del patrimonio cultural en cualquiera de sus tres categorías (arqueológicos, históricos y artísticos). También cabría señalar especialmente el carácter de obligatoriedad que debe tener esta ley para las instituciones, públicas y privadas en lo que se refiere a la elaboración de un inventario detallado de los objetos culturales que tienen en propiedad y a reportarlos en este formato a los institutos competentes.

Respecto a este instrumento que mencionamos, la ley vigente ya citada, establece en su Artículo 21, la creación de un Registro Público de Monumentos y Z onas Arqueológicos e Históricos, que depende del Instituto Nacional de Antropología e Historia. Empero no existe obligatoriedad, ya que la misma ley establece que la inscripción en los registros se hará de oficio o a petición de la parte interesada. Uno esperaría que el reglamento de 1975 de la citada ley, estableciera un formato o modelo para tramitar administrativamente dicho registro. Sin embargo en el Capítulo II artículo 17, de este Reglamento dedicado al registro, se establece que para la inscripción de monumentos muebles se anotarán:

1.La naturaleza del monumento y, en su caso el nombre con el que se le conozca;

2.La descripción del mueble y el lugar donde se encuentre;

3.El nombrey domicilio del propietario o, en su caso, de quien lo detente;

4.Los actos traslativos de dominio, cuando estos sean procedentes de acuerdo a la Ley; y

5.El cambio de destino del monumento, cuando se trate de propiedad federal. 6

Como se puede apreciar, no existe especificación en este registro sobre la presentación de fotografías o de descripciones más formales apegadas a la naturaleza del monumento mueble en cuestión. Esto aparecerá como condición solamente cuando se requiera obtener la certificación de autenticidad. Por otra parte la falta de un control más estricto en el caso específico de los bienes del patrimonio documental, propicia necesariamente el fácil traslado de dominio, legal o ilegal, especialmente el de aquellos bienes poco conocidos.

En una anécdota publicada recientemente al respecto, se lee:

A mi paso porla calle, me encontré sobre la acera, ala puerta deunalujosa residencia del Pedregal, una montaña de libros viejos, nada menos que justamente la edición completa de 1929 de la Enciclopedia universal ilustrada Espasa-Calpe. Esta maravilla de consulta para cualquier historiador, de alrededor de 70 libros, yacía abandonada junto con viejos tapetes y retacería de alfombranueva, que de acuerdo con mi olfato investigador, eran evidencias de un cambio de decoración de algún vecino. Algunos

6 INAH, unahistaia/ coordinador Julio César O livé Negrete. México : CONACULTA. INAH, 1995. Vol. 2, p. 327. 
transeúntes comenzamos a hojear los tomos y aquello terminó en rebatinga. A cabé por agenciarme una carretilla, e ir llenando la cajuela de mi coche, con el apoyo de un par de escuderos con quienes ganélabatalla, en aras del rescatey defensa de la cultura, frente a laúltima contienda con un taxista que se proponía venderlos en Tepito.7

El coleccionista, bibliófilo o mercader de libros y documentos, extranjero y nacional, sabe que en este país, a pesar de las normas establecidas, todavía puede encontrar verdaderas joyas bibliográficas arrumbadas, amontonadas y disponibles en las calles de esta ciudad. Sin embargo, por lo que toca al cumplimiento de la norma establecida, a pesar de que carezca de una redacción irrebatible en el terreno de lainterpretación, queda mucho camino por recorrer. Camino que podría iniciarse con el reconocimiento de la importancia que tienen los libros y documentos, antiguos y modernos, como bienes culturales que deben ser conservados y protegidos como testimonios del devenir histórico de esta nación.

La prohibición explícita de exportación definitiva de los monumentos históricos mencionados en las fracciones I, II y III del artículo $36^{\circ}$ de la Ley Federal, sólo se indica para aquéllos que son de propiedad particular y no para los que son de propiedad pública. La adscripción del patrimonio documental a este dominio, deberíaindicar su condición de inalienables, inembargables e imprescriptibles. Pero esta condición debería estar manifestada en relación con todos los bienes del patrimonio cultural mexicano cuya responsabilidad y tutela sean del dominio público, independientemente de su adscripción a cualquiera de las categorías establecidas.

En la lectura general, tanto de la Ley como de su Reglamento, se puede apreciar un notable interés por los bienes culturales que se reconocen en la categoría de arqueológicos en detrimento de las otras categorías. Incluso puede apreciarse el desinterés puesto en otros bienes, igualmente representativos de nuestro patrimonio cultural. También se observa esto en el elogio que se hace de la riqueza cultural, al distinguirse única o preponderantemente lo que corresponde al terreno arqueológico y artístico y dejar de lado lo que corresponde a lo histórico. ${ }^{8}$ La Ley constituye un cuerpo normativo de complicada interpretación que se vincula con otros ordenamientos y le da mayor importancia a otros trámites administrativos por encima del prioritario: su registro y su inventario. "En realidad, se haido tejiendo un entramado lleno de nudos difíciles de desatar. Se llenarían resmas de papel para describir puntualmente la situación y los tropiezos habidos en el tiempo." 9

Es decir, en lo que respecta a este inventario, esta norma tan singular debería: determinar la composición del instrumento de control de acuerdo con la naturalezadel

7 Gilda Cubillo Moreno. "El coleccionismo y la compra-venta de bienes culturales en México". En Memoria: reista mensual depdítica yaltura. No. 128 (octubre de 1999), p. 17.

8 Cf Felipe Solís. Patrimonio de la Humanidad: presencia de México en el mundo. En Méxicoend tiempa No. 33 (noviembre/ diciembre 1999).

9 Teresa Martínez Peñaloza. "Patrimonio Cultural, legislación y sociedad: encuentros y desencuentros." En Lasøiedadaivil frenteal patrimmioaltural. México :UNAM. Instituto de Investigaciones Estéticas, 1997. p. 23. 
bien en cuestión; la obligatoriedad de su conformación tanto para el terreno público como para el privado; la responsabilidad de la vigilancia y el cumplimiento de este registro, y la sanción meritoria que se deriva de esta última acción.

Este patrimonio documental no puede ser protegido con la Ley vigente en la mano, su valor cultural y la fragilidad de su naturaleza requiere de una urgente atención que garantice su conservación y conocimiento. "Este valor especialísimo requerirá una ley específica, bien un tratamiento legal complejo y sistemático y no [reducir su riquezay complejidad a una mera fracción normativa], a modo de apéndice, que plantea problemasjurídicos difíciles de resolver desde el momento en que se remite a normas generales de la ley que están pensados inicial y finalmente [...]"10 para otros bienes patrimoniales.

\section{EL PANORAMA CULTURAL Y LAS IN ST IT U CIONES DE CUSTODIA}

Si bien en México existe un conjunto de instituciones encargadas de la custodiay control de los bienes culturales y ha delimitado un marco jurídico de actuación y, por ende, de responsabilidad, el patrimonio documental vive un panorama institucional fragmentado que no posibilita la concreción de acciones generales y, por tanto, de responsabilidad nacional, que den por resultado una adecuada salvaguarda de esos objetos culturales.

Mencionamos ya la notoria ausencia en la ley vigente de las dos instituciones emblemáticas que custodian importantes bienes documentales: el Archivo G eneral de la Nación y la Biblioteca Nacional. La propia legislación que justifica y explica la naturaleza de ambas instituciones no permite realizar una lectura que establezca el lugar de los bienes patrimoniales que custodian.

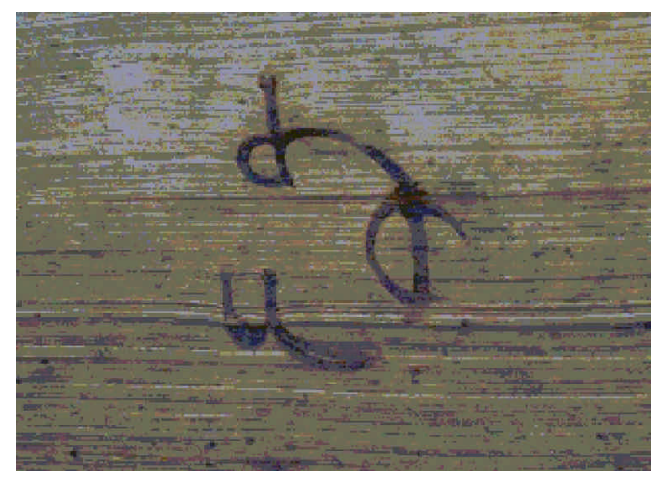

Marca de Fuego. Universidad Autónoma de Aguascalientes

Fotografía Idalia García

10 José María D esantes G uanter. Teønáyrégimenjuńdicœdeladbamentaaión Madrid : EUD EMA, 1987. p. 41. 
Por evidencia jurídica, tampoco existe la norma que establezca obligatoriedad para compilar el inventario y hacer el registro general de sus fondos, ni mucho menos señale la responsabilidad social que adquieren como custodios de esta riqueza aquellos que ahí laboran. Incluso el reconocimiento jurídico para la defensa del patrimonio cultural de este país, debería establecerse por entidades, no por sobre los bienes que custodian. Este reconocimiento únicamente debería establecerse para aquellos objetos de singular relevancia.

Por otro lado, es complicado conciliar a dos instituciones cuya dependencia orgánica es completamente bipolar: el Archivo depende de la Secretaría de G obernación y la Biblioteca de la Universidad Nacional Autónoma de México. ¿Cómo integrar los trabajos institucionales cuando estamos sometidos a estas características del panorama cultural de México?. Ciertamente bastaría con consolidar un acuerdo entre ambas instituciones, independientemente del marco legal de aplicación. Pero si este acuerdo no fuese elevado de categoría jurídica, su completa realización quedaría depositada en el interés y motivación de los directores responsables.

Pero quedaría un aspecto pendiente. Nos referimos a la legitimación de las acciones orientadas hacia el registro y el control de los bienes documentales, y al establecimiento de normas y modelos de aplicación general para éstos. Sin una norma jurídica que así lo determine, el proceso de registro e inventario de nuestro patrimonio documental siempre quedará relegado, puesto que no será considerado como una prioridad nacional encabezada por estas instituciones y depositada en ellas.

La cuestión jurídica relacionada con esta riqueza patrimonial ha sido poco analizada y menos aún especialmente evidenciada en México. El cambio de un ordenamiento jurídico no es una cuestión de modas y tendencias, sino de vigencias y especialmente de factibilidad, pues:

[...] lafunción del D erecho no es solamentela de mantener el orden cons-

tituido, sino también la de cambiarlo adaptándolo a los cambios sociales;

Tanto es así que todo ordenamiento jurídico provee algunos procedimientos destinados a regular la producción de normas nuevas para sustituir a las viejas. ${ }^{11}$

Resulta interesante en este sentido observar que nuestro ordenamiento jurídico no establece la necesidad de revisar su contenido y redacción basándose en el cumplimiento de metas prioritarias que permitan una adecuada salvaguarda. La problemática que enfrenta el patrimonio cultural de México ha cambiado en la medida en que se ha modificado nuestro sistema cultural. Sin embargo la naturaleza de los bienes a tutelar requiere mínimamente de la participación de todas las entidades que custodian dichos bienes, tal es el caso de la Biblioteca y el Archivo.

La propuesta panista presentada en abril pasado para reformar la ley vigente que protege el patrimonio cultural mexicano, posee las mismas carencias que este ordenamiento, como hemos señalado arriba. Sin embargo, tal proporción no produjo

11 Ibid p. 264. 
una reflexión seria sobre las problemáticas que aquejan a todos los bienes mexicanos de naturaleza cultural, y menos aún un efectivo análisis crítico de las instituciones encargadas de su custodia. Este debate únicamente defendió al INAH, a sus instituciones y a sus agremiados.

Sería necio negar la importante tarea que han desempañado ambos institutos en la defensa de los valores y símbolos de la cultura mexicana. Pero también sería sensato reconocer las limitaciones y enfocar la discusión, exactamente hacia donde encontremos las debilidades.

Pero una cosa es el funcionalismo, que es una teoría global de la sociedad [...] y otra el análisis funcional de una institución que puede perfectamente prescindir de esa especie de filosofía social que es el funcionalismo y que no es en absoluto incompatible con un análisis crítico de la institución fundado precisamente en la mayor o menor utilidad social de la función que esa institución cumple. ${ }^{12}$

Básicamente toda la discusión aquí reseñada nunca ha reconocido que seguimos teniendo un patrimonio cultural en riesgo, que nuestros bienes no están registrados en su totalidad, que las declaratorias no han alcanzado a objetos de distinta naturaleza, y que debe proponerse la participación jurídica de otras instituciones. En suma, no ha reconocido que garantizar la salvaguarda de estos bienes patrimoniales en su conjunto, independientemente de su naturaleza, requiere necesariamente del concierto jurídico entre instituciones.

D e entre estas discusiones extraigo una que cala más profundamente en mis reflexiones y preocupaciones:

Menos atención ha recibido un recurso de gran importancia científica y valor cultural: los acervos reunidos y resguardados por el INAH en todo el país. Entre ellos la colección osteológica (la mayor del país y una de las más importantes de América); las bibliotecas antropológicas e históricas (entre las que destaca la Biblioteca Nacional de Antropología e Historia); la colección de códices mesoamericanos (la más grande del mundo); las ceramotecas; las fototecas (uno de cuyos fondos es el mundialmente conocido Archivo Casasola); los archivos históricos (incluidoslos que guardan información novohispana y del siglo XIX) así como los informes arqueológicos; las fonotecas con registros lingǘsticos, entrevistas y música, etc. La iniciativa panista ignora simple y llanamente esa gran riqueza patrimonial y la deja legalmente desprotegida. ${ }^{13}$

Ante tales argumentaciones yo me preguntaría básicamente ¿dónde queda el reconocimiento y la protección legal de todos aquellos acervos documentales que no custodia el INAH? ¿Es que por esta condición son menos importantes? ¿Es que aca so la ley vigente determina esta adscripción administrativa para reconocer la valoración cultural del patrimonio cultural? Podría incluir muchas más preguntas de esta índole para seguir observando y probando que nuestro rico y diverso patrimonio

12 Norberto Bobbio. Op Cit p. 262.

13 "Acervos en riesgo" / coordinación Carlos G arcía Mora. En Equis alturaysoiedad No. 17 (septiembre 1999), p.II. 
documental carece de normas mínimas para su conservación y preservación; denormas mínimas de descripción e identificación, y básicamente, de un registro general que nos permita saber con certeza cuáles son, en dónde están y en qué condiciones se encuentran.

La ley vigente no permite identificar la importancia patrimonial de estos objetos culturales ni de las instituciones públicas o privadas que los custodian. Sería más fácil equiparar ambos bienes en la norma jurídica, libros y documentos, en una única categoría cuya pretensión fuese un inventario o censo dividido en secciones. Un patrimonio documental, como ya lo ha establecido laUNESCO, donde ambos objetos culturales y otros más estuviesen incluidos. ${ }^{14}$

Existe también la imperiosa necesidad de poner a disposición pública lainformación existente so bre los bienes del patrimonio cultural, como las declaratorias oficiales y los registros. Esto es así especialmente si reconocemos la importancia de lo expresado en los artículos primero y segundo de la Ley vigente, respecto a que el objeto de esta ley es de interés social y nacional y que sus disposiciones son de orden público. También la investigación, protección, conservación y recuperación de los monumentos arqueológicos, artísticos e históricos y de las zonas de monumentos son de utilidad y orden públicos.

La discusión sobre el patrimonio cultural de México no debe quedar en la demarcación de cotos de actividad, sino en un sano equilibrio de participación entre la sociedad, las instituciones, los poderes públicos y, también, la iniciativa privada. Un esfuerzo nacional organizado que permita sensibilizar y crear conciencia de la importancia que tiene la conservación pero también el conocimiento de esta riqueza cultural.

Además, únicamente podremos acercar este patrimonio a la sociedad que lo ha heredado mediante la elaboración de productos culturales (videos, facsimilares, tarjetas, agendas, calendarios, etcétera) que permitan, por un lado, su difusión y apreciación, y por el otro, la obtención de recursos que se utilicen para las tan necesarias campañas de restauración y conservación preventiva. Sin embargo nada se podrá hacer como tarea a largo plazo sin antes consolidar un marco jurídico de protección quereconozca todas estas necesidades, y quetambién establezcala norma de su propio crecimiento.

\section{LA PERSPECTIVA BIBLIOTECARIA PARA LA PROTECCIÓN DEL PATRIMO- NIO DOCUMENTAL}

La conservación y conocimiento de estos acervos que componen una parte esencial de nuestro patrimonio documental y, como tal, de nuestra memoria colectiva, representan un reto en este nuevo milenio para las diversas disciplinas que habrán de custodiar adecuadamente esta riqueza, especialmente la bibliotecologíay la archivística. Ambas disciplinas tienen una responsabilidad añadida en esta labor cultural, 14 José María D esantes Guanter. Op Cit p. 93. 
pues además de la responsabilidad que conllevan en la formación de especialistas para organizar estos universos de información, deben participar en la necesaria realización de investigación sobre objetos particulares, pero también debemos robustecer la presencia de estos bienes culturales dentro de las preocupaciones colectivas de los profesionistas. D e esta última acción, dependerá directa y especialmente el futuro de estos acervos y la participación de archivistas y bibliotecólogos en las tareas de salvaguarda.

Por otra parte es indudable que lainvestigación dela historia particular de cadauno de estos objetos culturales es una labor indispensable que complementa los procesos de valoración cultural. Este es otro espacio de la práctica profesional igualmente importante hacia el que deberíamos orientar también a las nuevas generaciones de profesionistas, con el mismo entusiasmo con que los encauzamos hacia el futuro y las nue vas tecnologías. Igualmente debería hacerse un espacio curricular en la formación profesional para proporcionar los conocimientos básicos pero fundamentales del mundo del libro antiguo en el caso de la bibliotecología. El archivo histórico en laformación archivística, tiene ya un espacio, aunque éste sea, ciertamente, limitado.

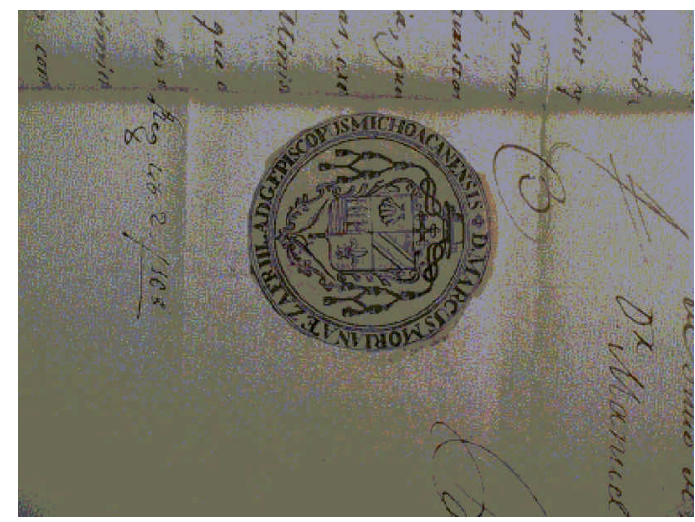

Colección Manuscritos. Biblioteca Eusebio Francisco Kinos Fotografía Idalia García

Nos referimos específicamente a que este conocimiento requerido, alcanza un límite superior al establecido por el mero proceso histórico. "Los textos escritos, y muy especialmente los libros, tienen un carácter bien distinto: están dotados, son histónicos En ellos se conservan las formas de la vida pretérita, las referencias explícitas a sucesos y personas de diversas épocas, la lengua del tiempo en que fueron escritos." 15 E s decir, el conocimiento del mundo del libro antiguo, requiere deuna

15 Julián Marías. "El libro en el pensamiento y la continuidad histórica”. En Laailturadd libro/ coordinado por Fernando Lázaro Carreter. Madrid : Fundación G ermán Sánchez Ruipérez : Pirámide, c1983. p. 69. 
aproximación al objeto mismo, a la naturaleza de su composición. Solamente con "la adquisición de un conocimiento adecuado del ámbito histórico y cultural en que se produjeron los libros, unido a una capacidad técnica suficiente para garantizar su tratamiento y uso,"16 le daremos al profesionista la oportunidad de escoger libremente la decisión de dedicarse al objeto más representativo del patrimonio cultural de la humanidad: el libro antiguo.

Pero para ello será necesario entender la diferencia que existe entre un material antiguo y uno moderno, comprensión necesaria para darle un adecuado tratamiento en el universo de la información. La suma de estos conocimientos permitirá percatarse de la importancia que tiene la valoración cultural de tan importantes objetos en su dimensión patrimonial.

Lamentablemente en la valoración del patrimonio cultural siempre existirán objetos que por sus particularidades y representación requerirán de mayor atención que otros. É sta es una situación que también debe conocer el alumno, ya que en algunas ocasiones de este conocimiento dependerá la permanencia de los objetos; en suma significa entender que una gran parte de estos objetos son algo más que libros viejosy por tanto inservibles. Empero es la investigación de estos bienes patrimoniales la que ha demostrado ser el arma más eficaz para conocer y apreciar su importancia testimonial, y asimismo para crear una conciencia social capaz de demandar su adecuada salvaguarda. Esta función intermediaria entre una herencia cultural y una sociedad moderna, sigue siendo responsabilidad de los especialistas, son éstos quienes tendrán mayores argumentos para consolidarle un espacio propio entre las instituciones y poderes políticos y garantizar su permanencia y valoración para el futuro.

El mundo del patrimonio documental se convierte así en un reto que sobrepasa las fronteras de su propio conocimiento. Además debe conseguirse el pleno reconocimiento del patrimonio documental como bien cultural de similar relevancia que otros de naturaleza distinta, como lo son los bienes inmuebles. Esta tarea debe perseguir especialmentela comprensión de que su protección es sobre todo un derecho cultural y por tanto un deber social que sólo se conseguirá consolidando un cuerpo jurídico elaborado, ex profeso con la naturaleza propia de estos materiales, lo que a su vez garantizará la permanencia de su significado y representación en el tiempo.

Latarea futuro parala comunidad bibliotecaria, tanto técnica como profesional, para contribuir al aseguramiento de la salvaguarda del patrimonio documental en México incluye así numerosas labores: la participación en la elaboración de una propuesta legislativa que contenga todos los aspectos y problemáticas que afectan al patrimonio documental (en lo que corresponde a bienes bibliográficos); la redacción de normas generales para inventariar eidentificar los materiales; la discusión y adopción de un modelo compartido de descripción bibliográfica; la preparación de normas generales de conservación preventiva, de acceso y consulta, etcétera. En suma,

16 Norberto Bobbio. Contriburióna la teeńa dd Deeeho Madrid : D ebate, 1990, p. 276-275. 
requerirá de una verdadera colaboración entre disciplinas, pero sustancialmente de un proyecto coordinado que permita compartir todos los recursos disponibles.

D ebemos en efecto reconocer que somos en gran parte responsables de la situación tan lamentable en que se encuentra nuestro patrimonio documental. Nuestra ausencia de toda discusión que los involucre, especialmente desde su perspectiva patrimonial, no favorece en nada su conservación. En los resolutivos del "Foro antropología, historia, patrimonio y sociedad" publicado en algunos periódicos el 4 de agosto de 1999, se puede leer lo siguiente en el punto 9. "Es inaceptable que se pretenda desproteger legalmente a los códices, murales y demás testimonios pictóricos prehispánicos y coloniales y a los archivos, acervos doumentalesybibliøááicos di sigo XVI al XIX como lo hace la iniciativa de ley. Es imprescindible que las diversas instancias oficiales reconozcan la importancia de este legado histónico e impulsen su resguardo, conservación y estudio." ${ }^{17}$ A esta interesante conclusión se llegó sin la mediación ni participación de los bibliotecarios de México, algo queresulta en extremo lamentable.

Frente a todas las acciones colectivas que se observan últimamente en relación con discusiones que afectan la vida cultural en México, nuestra ausencia es imperdonable, duele igual que cuando se mira la hoja, desgarrada, mutilada, en peligro de extinción, de un libro antiguo en territorio mexicano. El pasado nos reclama simplemente una consideración: su inclusión entre nuestras diversas prioridades.

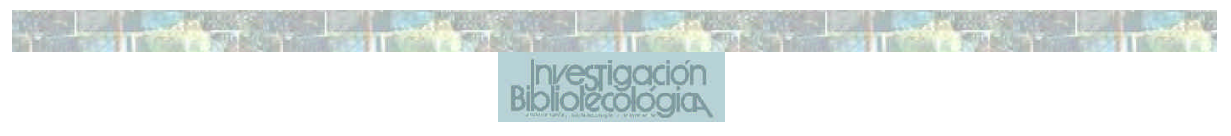

17 Lo destacado en negritas es mío. 